\title{
Светокультура
}

\section{О ВЛИЯНИИ РАЗЛИЧНЫХ ИСТОЧНИКОВ СВЕТА \\ НА ФОТОСИНТЕТИЧЕСКИЕ ПАРАМЕТРЫ ПРОДУКЦИОННОГО ПРОЦЕССА У Cucumis sativus L. (ГИБРИД ТРИСТАН F1) В УСЛОВИЯХ АЭРОПОННОГО ФИТОТРОНА}

\author{
Л.Ю. МАРТИРОСЯН 1,3 , А.А. КОСОБРЮХОВ1, 2, В.В. МАРТИРОСЯН1, \\ Ю.Ц. МАРТИРОСЯН ${ }^{1,3}, 3$
}

\begin{abstract}
Глобальные изменения климата и антропогенное загрязнение окружающей среды создают серьезные проблемы для сельскохозяйственных производителей, и последствия этих процессов влияют на производство продуктов как прямо, так и косвенно. Засуха или подтопление полей, появление новых болезней и вредителей, сокращение площадей для сельскохозяйственного производства создают серьезные проблемы в обеспечении продовольствием в условиях роста населения. При этом более половины населения мира проживает в городах, и ожидается, что к 2050 году эта доля увеличится до $67 \%$. Для удовлетворения потребностей мегаполисов необходимы нестандартные подходы и технологии для увеличения объемов производства свежих овощей, фруктов, ягод. Вертикальное растениеводство, или так называемая «городская ферма», - перспективный ресурсосберегающий способ компактного, многоярусного выращивания растений, особенно зеленных культур, овощей, лекарственных и декоративных растений. С использованием гидропоники и аэропоники становится возможным ведение сельского хозяйства нового типа (без применения почвы), которое сочетает в себе биотехнологию, промышленную архитектуру, дизайн, успешно интегрируется в городскую инфраструктуру. Существенное увеличение производства и повышение урожайности основных продовольственных овощных культур, особенно в условиях «городской фермы», невозможно без изучения потребностей растений в свете, минеральном питании и в других, не менее важных (температура, влажность, содержание $\mathrm{CO}_{2}$ ) факторах. В условиях фитотрона, имитирующего модель «городская ферма», мы исследовали возможности применения традиционных для защищенного грунта источников света (ДНаТ-600) и альтернативных светодиодных фитосветильников (СДО) для выращивания растений огурца (Cucumis sativus L., гибрид Тристан $\mathrm{F}_{1}$ ) как коммерчески значимой культуры защищенного грунта (всего четыре варианта опыта). На примере реакции растений огурца изучали влияние светового излучения на фотосинтез и, в конечном итоге, на продукционный процесс. При интенсивности облучения 305 и 413 мкмоль фотонов м $^{-2} \cdot \mathrm{c}^{-1}$ (во 2-м и 3-м вариантах опыта, соответственно светодиодный облучатель и лампы ДНаТ-600) и температуре 25 и $26^{\circ} \mathrm{C}$ формируется фотосинтетический аппарат, способный эффективно работать при повышении интенсивности света до 1200 мкмоль фотонов $\mathbf{M}^{-2} \cdot \mathrm{c}^{-1}$. Было показано, что СДО (2-й вариант) можно использовать как единственный источник света при выращивании растений огурца в условиях «городская ферма». Эти облучатели характеризуются меньшей долей синего $\left(\lambda_{\max }=450\right.$ нм) и дальнего красного $\left(\lambda \max =730\right.$ нм) света и болышей долей красного $\left(\lambda_{\max }=660\right.$ нм $)$ света в спектре. Однако для получения раннего урожая предпочтительнее использовать ДНаТ-600 с применением стандартного приема приспускания стебля. Вегетационный период при облучении ДНаТ-600 в условиях аэропонного фитотрона, моделирующих «городскую ферму» (с ограничением по высоте размещения фитосветильника 1,5 м), без использования приема приспускания, заканчивался на 12 сут раныше, чем под светодиодными облучателями. Тем не менее выход урожая за время вегетации в варианте с ДНаТ-600 был выше, чем в вариантах опыта, где использовались светодиодные облучатели, при одинаковых энергозатратах. Полученные данные могут быть полезными для проектирования и создания современных биотехнологических предприятий типа «городская ферма» (производство продуктов питания) и предприятий, занимающихся биофармингом.
\end{abstract}

Ключевые слова: Cucumis sativus L., фотосинтетический аппарат, светодиодные фитосветильники, ростовые процессы, аэропонный фитотрон, городская ферма.

Правильный выбор светового режима выращивания растений с учетом их видовых особенностей, стадии развития, физиологического состояния важен для получения продукции в условиях светокультуры (1-3). При этом одним из основных источников света становятся светодиодные облучатели (СДО) (4-6). Они позволяют, используя программы управления световыми условиями выращивания, направленно воздействовать на

* Работа выполнена по государственному заданию № 0574-2019-0002.

934 
продукционный процесс, ускоряя или замедляя определенные фазы роста и развития растений (7-9).

В настоящее время коммерчески доступны светодиоды с максимумами излучения во всех областях спектра. Сочетание красных и синих СДО наиболее часто применяется для обеспечения роста и развития многих растений, особенно зеленных культур $(10,11)$. Использование этих светодиодных облучателей положительно сказывается на повышении скорости фотосинтеза и накоплении биомассы растений $(12,13)$. Красный диапазон спектра (KC) важен для нормального роста и развития растений, формирования фотосинтетического аппарата и его дальнейшей активности, синтеза и накопления фотоассимилятов $(6,14,15)$. Синий диапазон спектра облучения (CC) необходим для формирования хлоропластов, накопления хлорофилла, раскрытия устьиц и фотоморфогенеза растений (16). Для разных культур соотношение красного и синего спектров облучения колеблется в значительном диапазоне - от 2:1 до 9:1 $(8,17)$. Наряду с КС и СС, в спектре облучения растений должны присутствовать и другие области. Ранее наиболее эффективным считалось следующее соотношение участков спектра в излучении облучателей: $25-30$ \% в синей области (СС), $20 \%$ - в зеленой (3С) и 50-55 \% - в красной (KC) (18). Такое облучение обеспечивает рост, морфогенез и продуктивность растений. Вместе с тем важно присутствие других спектральных областей - небольшой доли ультрафиолетового (УФ), дальнего красного (ДКС) и инфракрасного света (ИК). В работе М. Qian с соавт. (2) УФ-свет использовали в качестве регулятора роста у растений огурца, наличие УФ-облучения приводило к повышению степени раскрытия устьиц, скорости фотосинтеза и транспирации. Предварительная обработка УФ-А (длинноволновое излучение) позволяет получать крепкую рассаду томата, которая подходит для транспортировки в производственные питомники и теплицы (19).

Изменение соотношения КС/ДКС может оказывать значительный эффект на морфологию растений (20), активность ряда физиологических процессов $(21,22)$. При освещении растений КС ( $\lambda \max =660$ нм) стабильная форма фитохрома (Фк, фитохром красный) преобразуется в Фдк (фитохром дальний красный). Повышение доли дальнего красного света $(\lambda \max =730$ нм) приводит к преобразованию Фдк обратно в форму Фк. В результате наблюдаются различные изменения, например удлинение гипокотиля, увеличение длины междоузлий, распределение ассимилятов.

О важности определенных областей спектра свидетельствуют работы (23-25), показывающие, что изменение максимумов облучения растений даже в пределах одного спектрального режима - красного, зеленого, синего значительно влияет на характеристики продукционного процесса.

У разных культур соотношение диапазонов спектрального облучения, наиболее благоприятное для выращивания растений, неодинаково (25). В условиях многоярусных аэропонных «городских ферм» возникают дополнительные пространственные ограничения для роста в высоту, которые также следует учитывать (26). Поэтому физиологические процессы, обусловливающие необходимость изменения спектра облучения в зависимости от культуры, оптимизация светового режима выращивания продолжают оставаться в центре внимания $(27,28)$ и требуют дальнейшего исследования.

В настоящей работе мы показали, что СДО можно успешно применять для регуляции ростовых процессов, однако энергоэффективность их производственного использования остается под вопросом. В нашем 
исследовании облучение натриевыми лампами, спектр которых приближен к солнечному, больше способствовало ускорению роста и развития растений по сравнению с облучением СДО той же мощности. Исключение составил один вариант, в котором сочетание спектральных характеристик СДО и температуры оказалось оптимальным для роста, развития и формирования продуктивности растений, сопоставимой с таковой при применении натриевых ламп высокого давления (ДНаТ-600). Следует учитывать, что у ДНаТ-600 в спектре велика доля инфракрасного излучения, что в условиях «городских ферм» может приводить к тепловому шоку растений. Избегать этого позволяет прием приспускания в желоба аэропонногидропонной установки (патенты RU 88246U1, RU 131569 U1).

Цель работы - сравнительное изучение действия светодиодного облучения (СДО) разного спектрального состава и интенсивности и натриевых ламп высокого давления (ДнаТ-600) (при одинаковой энергетической мощности всех облучателей) на параметры продукционного процесса у растений огурца в условиях аэропонного выращивания по модели «городская ферма».

Методика. Исследования проводили на растениях огурца (Cucumis sativus L.) гибрида Тристан F1 («Enza Zaden», Нидерланды). Гибрид Тристан F1 формирует сбалансированные растения генеративного типа со стабильным (без выраженных перерывов) плодоношением. Гибрид требователен к относительной влажности воздуха во все периоды развития и плодоношения. Плоды (длина 22-25 см, масса 260土20 г) характеризуются очень высокой выровненностью и товарностью, которая приближается к 100 \% (28).

Рассаду получали из предварительно подготовленных семян (патенты RU 180527U1, RU 2675932C1, RU 2708829C1) в разработанной нами аэропонной установке (RU 199457U1) под светодиодными облучателями при интенсивности света $100 \pm 5$ мкмоль фотонов $\cdot \mathrm{M}^{-2} \cdot \mathrm{c}^{-1}$ (16 ч день/8 ч ночь). На 19-20-е сут (в фазу 3-4 настоящих листьев) растения в держателях переносили в фитотрон и помещали в желоба разработанных нами аэропонных модулей (RU 88246U1, RU 131569 U1) под разработанные нами светодиодные облучатели с разными спектральными характеристиками (1-й, 2-й и 4-й варианты опыта) и под лампы ДНаТ-600 (MASTER GreenPower 600W 400V, «Philips», Нидерланды; 3-й вариант опыта). Фитотронное помещение объемом $120 \mathrm{~m}^{3}$ было разделено на четыре одинаковых отсека (по $30 \mathrm{~m}^{3}$ в каждом варианте опыта) с помощью светонепроницаемых светоотражающих экранов. Расстояние от осветителей до поверхности желобов (посадочное поле) составляло 1,5 м (с учетом ограничений расположения осветителей по высоте в условиях «городской фермы»), плотность размещения растений в желобах аэропонных модулей $-4,8$ шт/м² (12 растений на вариант).

Задаваемые температурные режимы воздушной среды в фитотронном помещении соответствовали рекомендуемым для гибрида Тристан $F_{1}$ и зависели от фазы развития растения и технологии выращивания. Во всех вариантах первые 2-3 сут после высадки растений температура круглосуточно оставалась пониженной $\left(20-22^{\circ} \mathrm{C}\right)$, затем переходили на постоянный температурный режим - $25 \pm 1{ }^{\circ} \mathrm{C}$ (день) $/ 20 \pm 1{ }^{\circ} \mathrm{C}$ (ночь) с фотопериодом 16 ч (день)/8 ч (ночь). Температурный режим воздушной среды поддерживали в автоматическом режиме с помощью системы кондиционирования и вентиляции, корневой зоны $\left(21 \pm 1^{\circ} \mathrm{C}\right)-$ посредством охлаждения питательного раствора в автоматическом режиме при помощи устройства G-30 Polar («UBC Group», Китай). Влажность в фитотронном помещении $(75 \pm 5 \%)$ соответствовала оптимальной для гибрида. Концентрация $\mathrm{CO}_{2}$ в 
воздухе составляла $420 \pm 22$ мкмоль $\mathrm{CO}_{2} \cdot$ моль ${ }^{-1}$.

Температуру, относительную влажность, концентрацию $\mathrm{CO}_{2}$ контролировали с помощью беспроводного датчика E+E EE244 («E+E Elektronik», Австрия), который был интегрирован в систему управления технологическими процессами в фитотроне. Спектральные параметры контролировали с помощью спектрометра ASENSEtek PG100N («UPRtek Corp.», Тайвань).

Питательный раствор готовили на основе коммерческих удобрений («Yara International ASA», Норвегия). Использовали удобрение марки Kristalon огуречный $\left(\mathrm{N}_{14} \mathrm{P}_{11} \mathrm{~K} 31\right)$, нитрат кальция, нитрат магния с концентрацией основного удобрения 1 г/л, $\mathrm{Ca}\left(\mathrm{NO}_{3}\right)_{2}-0,8$ г/л, $\mathrm{Mg}\left(\mathrm{NO}_{3}\right)_{2}-0,3$ г/л; pH раствора корректировали ортофосфорной кислотой (х.ч., ООО «ХимМед», Россия). Раствор в виде мелкодисперсного аэрозоля подавали из баков с помощью насосов высокого давления и специальных форсунок непосредственно в корневую зону (каждый вариант опыта имел индивидуальный контур подачи питательного раствора). Затем конденсированный раствор стекал по желобу обратно в баки. Периоды подачи питательного раствора чередовались с периодами без подачи, во время которых происходила аэрация корневой системы растений. Гибрид обладает мощной и активной корневой системой, но, по данным оригинатора («Enza Zaden», Нидерланды), не переносит высоких концентраций солей, поэтому в эксперименте контролировали оптимальные значения электропроводности питательного раствора $(2,3 \pm 0,2$ мСм/см, pH 5,8 $\pm 0,2)$. Использовали $\mathrm{pH}$ электроды ST320, кондуктометрические электроды STCON3 («OHAUS Corp.», США), которые были интегрированы в систему управления технологическими процессами выращивания растений в фитотроне.

Интенсивность фотосинтеза определяли на 10-е сут вегетации и перед наступлением периода плодоношения на 20-е сут вегетации, на 20-е сут также измеряли параметры переменной флуоресценции хлорофилла a (Chl a). Измерения проводили в листьях 2-го и 3-го верхних ярусов на растениях, имеющих 10-14 ярусов листьев.

Активность фотосинтеза под светодиодными облучателями и лампами ДНаТ-600 оценивали по скорости СО2-обмена листьев с помощью переносного инфракрасного газоанализатора Lcpro+ («ADC BioScientific, Ltd», Beликобритания) при интенсивности света 300 мкмоль фотонов $\cdot \mathrm{M}^{-2} \cdot \mathrm{c}^{-1}$, a также при световом насыщении 1200 мкмоль фотонов $\cdot \mathrm{M}^{-2} \cdot \mathrm{c}^{-1}$. Зависимость скорости фотосинтеза от интенсивности света учитывали в диапазоне от 0 до 1200 мкмоль фотонов $\cdot \mathrm{M}^{-2} \cdot \mathrm{c}^{-1}$ при концентрации $\mathrm{CO}_{2}$ в воздухе $420 \pm 22$ мкмоль $\mathrm{CO}_{2} \cdot$ моль ${ }^{-1}$. Для этого последовательно повышали уровень интенсивности света с 0 до 1200 мкмоль фотонов $\cdot \mathrm{M}^{-2} \cdot \mathrm{c}^{-1}$. Световую кривую аппроксимировали моделью J.L. Prioul и P. Chartier (29) с использованием программы Photosyn Assistant (http://www.ddsci.com/) (30).

Для изучения реакций световой стадии фотосинтеза был использован метод переменной флуоресценции Chl a, характеризующий активность фотосинтетической системы II (ФС II) (31). Переменную флуоресценцию регистрировали с помощью портативного РАМ флуориметра (РАM-Junior, «Heinz Walz GmbH», Германия). Листья в течение 20 мин находились в темноте, после чего измеряли уровень минимальной $\left(\mathrm{Fo}_{\mathrm{o}}\right)$ и максимальной $(\mathrm{Fm})$ флуоресценции. Потенциальный квантовый выход ФС II находили как $\mathrm{F}_{\mathrm{v}} / \mathrm{Fm}_{\mathrm{m}}=\left(\mathrm{Fm}_{\mathrm{m}}-\mathrm{F}_{\mathrm{o}}\right) / \mathrm{Fm}_{\mathrm{m}}$, где $\mathrm{F}_{\mathrm{v}}-$ переменная флуоресценция. Реальный квантовый выход ФС II - Y(II) рассчитывали по формуле: $\mathrm{Y}(\mathrm{II})=\left(\mathrm{F}^{\prime} \mathrm{m}-\mathrm{Ft}\right) / \mathrm{F}^{\prime} \mathrm{m}$, 
где $\mathrm{F}^{\prime} \mathrm{m}$ - максимальная флуоресценция $\mathrm{Chl}$ а в адаптированных к свету образцах, $\mathrm{F}_{\mathrm{t}}$ - стационарный уровень флуоресценции Chl а в адаптированных к свету образцах. Значения коэффициента нефотохимического тушения флуоресценции Chl a ФС II (NPQ) определяли по формуле: NPQ $=\left(F_{m}-F_{m}^{\prime}\right) / F^{\prime}$. Относительную скорость транспорта электронов через ФС II рассчитывали как $\mathrm{ETR}=\mathrm{Y}(\mathrm{II}) \times \mathrm{PPFD} \times 0,5$, где $\mathrm{PPFD}-$ плотность потока квантов фотосинтетически активной радиации (ФАР).

Растения выращивали в один стебель, все боковые побеги удаляли. Для сохранения единообразия посадок растения не приспускали (в отличие от технологии, обычно применяемой в теплицах). Расположение стебля поддерживали строго вертикально, чтобы избегать взаимного затенения растений. Первый урожай получали на 38-42 сут после посадки. Собирали плоды с массой около 220 г. Отдача урожая происходила равномерно на протяжении вегетации и была наибольшей со среднего яруса (на высоте примерно 80-100 см).

Было проведено три цикла выращивания растений. Поскольку в серии опытов общие закономерности не различалась, представлены данные одного цикла (по урожайности приведены средние данные по трем циклам). При определении активности фотосинтеза и переменной флуоресценции Chl а размер выборки (n) был равен 8, аналитическая повторность измерений в экспериментах 4-5-кратная. Статистическую обработку проводили с помощью программы Statistica Base («StatSoft Inc.», США). В таблицах приведены средние арифметические значения $(M)$ со стандартной ошибкой $( \pm \mathrm{SEM})$. Достоверность различий определяли по $t$-критерию Стьюдента при $\mathrm{P}=0,95$.

Результаты. В задачу работы входила оценка интенсивности газообмена $\mathrm{CO}_{2}$, активности световой стадии фотосинтеза (по показателям переменной флуоресценции $\mathrm{Chl}$ a) и определение урожайности растений огурца, длительно выращиваемых методом аэропоники в фитотроне под светодиодными облучателями или лампами ДНаТ-600 с задаваемыми интенсивностью и спектральным составом облучения (1-4-й варианты опыта, рис.).

По вариантам опыта (1-й, 2-й, 3-й и 4-й) уровни интенсивности света в области 400-780 нм составляли соответственно 193 $\pm 7,0 ; 305 \pm 12,5$; $418 \pm 47,6$ и $309 \pm 11$ мкмоль фотонов $\cdot \mathrm{M}^{-2} \cdot \mathrm{c}^{-1}$ (табл. 1). Энергетическая мощность всех источников облучения составляла 1200 Вт, но в 1-м варианте светодиодный светильник диммировали до 75 \% от исходной мощности (см. табл. 1). У светодиодных облучателей спектры в 1-м и 4-м вариантах отличались от спектра во 2-м варианте в ближней инфракрасной области 701-780 нм (уменьшение облучения на 12\%) и в области 400-499 нм (увеличение на 12 \%). В результате в 1-м и 4-м вариантах доля синего света была несколько выше, чем во 2-м варианте.

При интенсивности света 300 мкмоль фотонов $\cdot \mathrm{M}^{-2} \cdot \mathrm{c}^{-1}$ скорость фотосинтеза по вариантам опыта составляла соответственно $4,1 \pm 0,2 ; 5,2 \pm 0,3$; $5,6 \pm 0,5$ и 4,7 $\pm 0,4$ мкмоль $\mathrm{CO}_{2} \cdot \mathrm{M}^{-2} \cdot \mathrm{c}^{-1}$. При 1200 мкмоль фотонов $\cdot \mathrm{M}^{-2} \cdot \mathrm{c}^{-1}$ растения во 2-м и 3-м вариантах показывали бо́льшие скорости газообмена $\left(7,9 \pm 0,5\right.$ и 7,6 $\pm 0,6$ мкмоль $\left.\mathrm{CO}_{2} \cdot \mathrm{M}^{-2} \cdot \mathrm{c}^{-1}\right)$, чем растения в $1-\mathrm{M}$ варианте $(75 \%$ от исходной мошности светодиода) и в 4-м варианте - соответственно

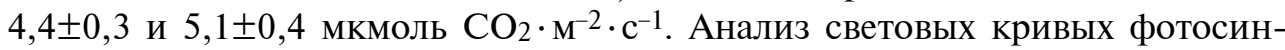
теза (табл. 2) позволяет оценить баланс между поглощением $\mathrm{CO}_{2}$ и его выделением в процессе темнового дыхания. 
1-й в а р а и н т

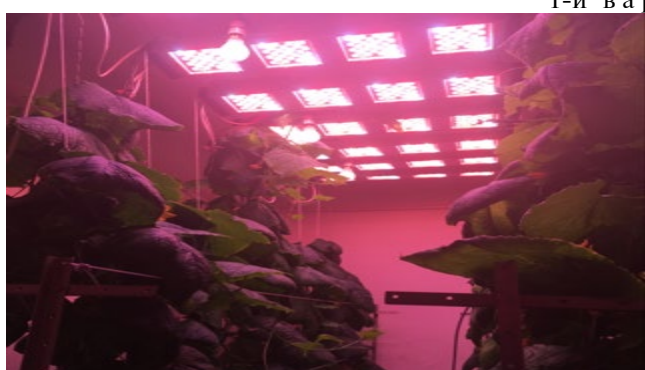

Ref:: McCREES ACTION SPECTRUM

2-й в а р а и т
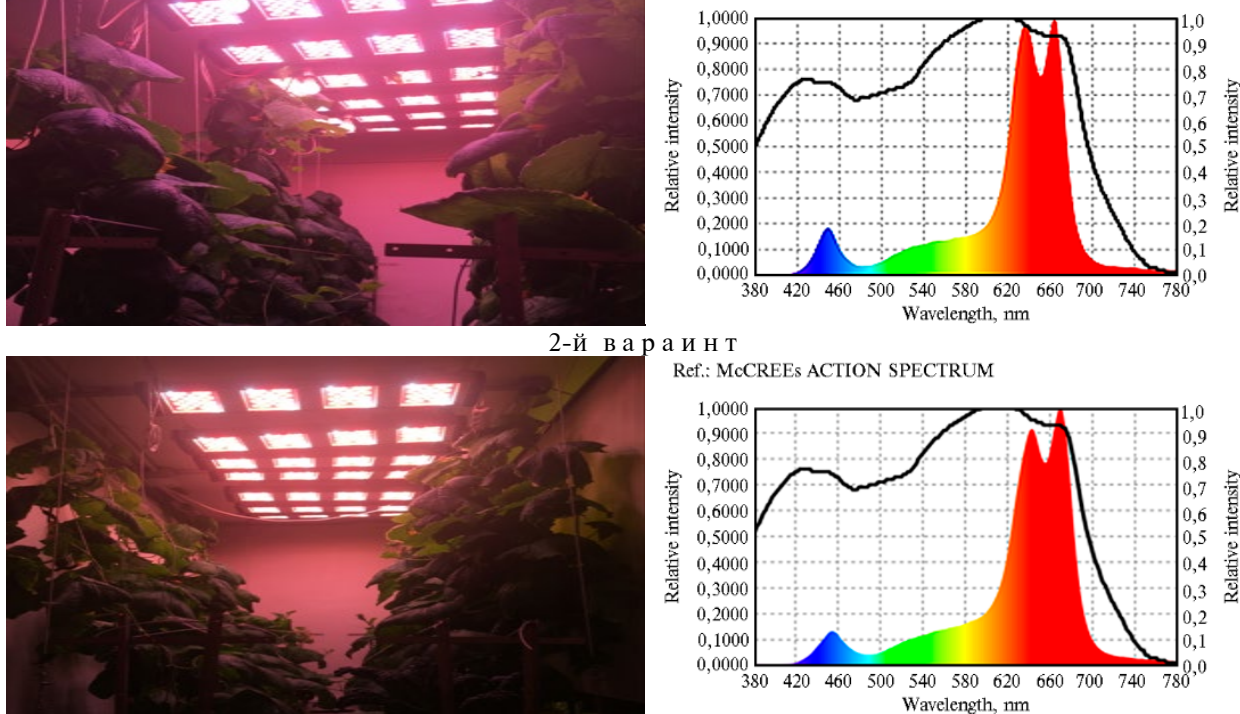

Ref.: MCCREES ACTION SPECTRUM

3-й в а р а и н т

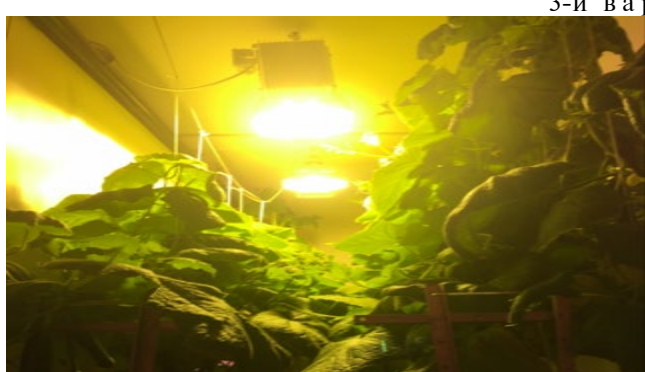

Ref.: MCCREES ACTION SPECTRUM

4-й в а ра и н т
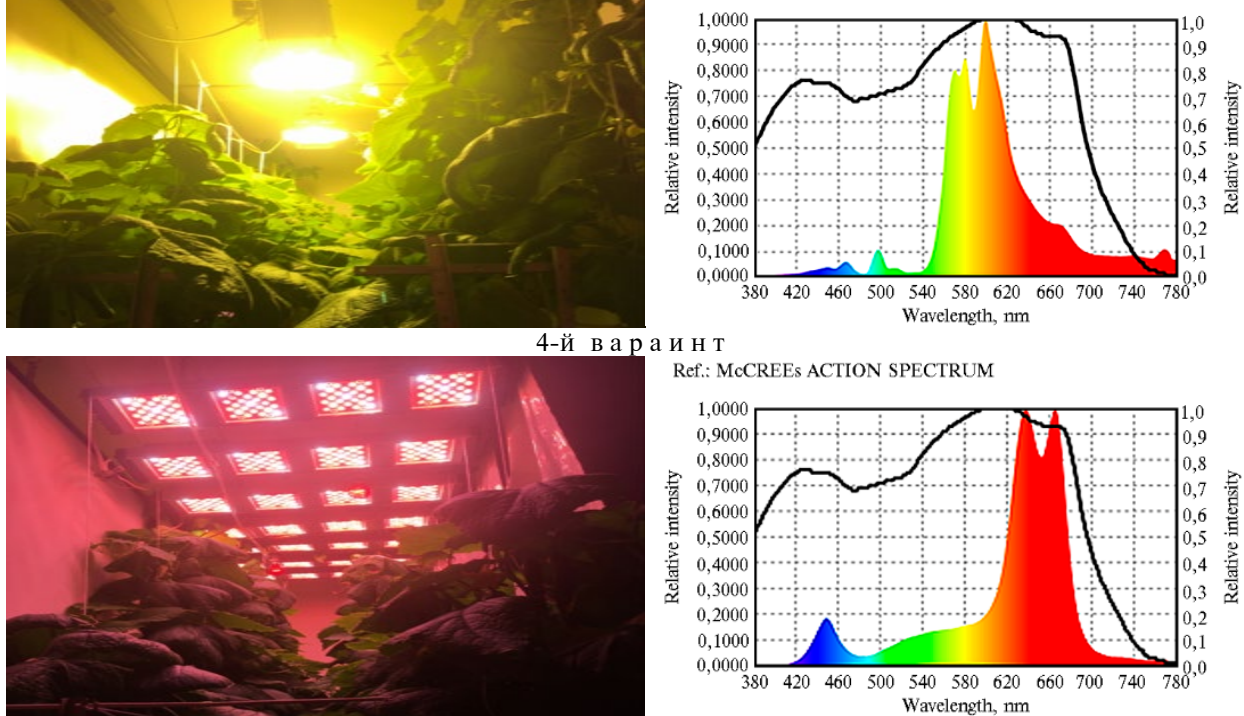

Ref.: McCREES ACTION SPECTRUM

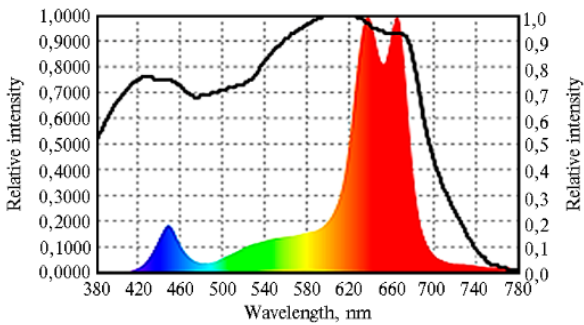

Спектральные характеристики светодиодных облучателей и ламп ДНаТ-600 при выращивании растений огурца (Cucumis sativus L., гибрид Тристан F1) методом аэропоники в фитотроне. Спектральный состав фитосветильников по вариантам опыта см. таблицу. 1.

\section{1. Энергетическая мощность (Р) и спектральные характеристики фитосветиль- ников по вариантам опыта при выращивании растений огурца (Cucumis sa- tivus L., гибрид Tристан F1) методом аэропоники в фитотроне}

\begin{tabular}{|c|c|c|c|c|}
\hline \multirow{2}{*}{$\begin{array}{l}\text { Диапазон } \\
\text { спектра, нм }\end{array}$} & \multicolumn{4}{|c|}{ Интенсивность света, мкмоль фотонов $\cdot \mathrm{M}^{-2} \cdot \mathrm{c}^{-1}$} \\
\hline & $1-и ̆ ~(P=945$ Вт) & 2-й $(\mathrm{P}=1200$ Вт) & 3-й $(P=1200$ & 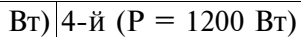 \\
\hline PPFD (400-700) & 193,00 & 304,86 & 412,98 & 309,02 \\
\hline PPFD IR (701-780) & 7,227 & 12,432 & 47,650 & 10,955 \\
\hline PPFD R (600-700) & 153,03 & 245,59 & 207,05 & 245,94 \\
\hline PPFD G (500-599) & 28,224 & 43,831 & 190,58 & 44,329 \\
\hline PPFD B (400-499) & 11,748 & 15,437 & 15,348 & 18,749 \\
\hline PPFD UV (380-399) & 0,0579 & 0,1420 & 0,6102 & 0,1087 \\
\hline Итого PPFD (380-780) & 200,28 & 317,34 & 461,43 & 320,08 \\
\hline
\end{tabular}


2. Анализ световых кривых СО2-газообмена листьев у растений огурца (Cucumis sativus L., гибрид Tристан F1) при выращивании методом аэропоники в фитотроне при разных световых и температурных режимах по вариантам опыта $(n=8$, аналитическая повторность измерений 5-кратная, $M \pm \mathrm{SEM}$ )

\begin{tabular}{|c|c|c|c|c|}
\hline етр & $\begin{array}{c}1-и ̆, \\
75 \%, 23{ }^{\circ} \mathrm{C}\end{array}$ & \begin{tabular}{c|}
$2-$-й, \\
$100 \%, 25^{\circ} \mathrm{C}$
\end{tabular} & $\begin{array}{c}3-и ̆, \\
100 \%, 26^{\circ} \mathrm{C}\end{array}$ & $\begin{array}{c}\text { 4-й, } \\
100 \%, 24^{\circ} \mathrm{C}\end{array}$ \\
\hline $\begin{array}{ll}\mathrm{aKCl} \\
\text { KMOJ }\end{array}$ & $4,4 \pm 0,4^{\mathrm{a}}$ & $7,9 \pm 0,5^{b}$ & $7,6 \pm 0,6^{b}$ & $5,1 \pm 0,5^{\mathrm{a}}$ \\
\hline $\begin{array}{l}\text { ового д } \\
\mathrm{I}^{-2} \cdot \mathrm{c}^{-1}\end{array}$ & $-1,3 \pm 0,3^{\mathrm{a}}$ & $-0,9 \pm 0,2^{\mathrm{a}}$ & $-2,5 \pm 0,3^{\mathrm{b}}$ & $-2,0 \pm 0,4^{b}$ \\
\hline дд ф & $0,039 \pm 0$ & $0,024 \pm$ & $0,036 \pm 0,00$ & $0,046 \pm 0,016$ \\
\hline $\begin{array}{l}\text { Інте } \\
\text { ривс }\end{array}$ & $144 \pm 11^{\mathrm{a}}$ & $363 \pm 17^{b}$ & $278 \pm 17^{c}$ & $423 \pm 19^{d}$ \\
\hline $\begin{array}{l}\text { Световой компенсационни } \\
\text { мкмоль фотонов } \mathrm{M}^{-2} \cdot \mathrm{c}^{-1}\end{array}$ & $32 \pm 7^{a}$ & $36 \pm 5^{\mathrm{a}}$ & $69 \pm 6^{\mathrm{b}}$ & $153 \pm 8^{c}$ \\
\hline \multicolumn{5}{|c|}{$\begin{array}{l}\text { П р и м е ч а н и е. Указаны проценты от исходной энергетической мощности светильников (1200 Вт) и } \\
\text { фактические температуры, которые устанавливались в отсеке фитотрона в зависимости от типа и ис- } \\
\text { пользуемой мощности светильника. Характеристики фитосветильников по вариантам опыта см. рисунок, } \\
\text { таблицу } 1 \text {. } \\
\text { a, b, с, d Средние значения в строке, отмеченные одинаковой буквой, статистически значимо не различаются } \\
\text { при р } \leq 0,05 \text {. }\end{array}$} \\
\hline
\end{tabular}

Во всех вариантах эксперимента растения имели положительный углекислотный баланс. В абсолютных значениях разница между поглощением и выделением $\mathrm{CO}_{2}$ в процессах фотосинтеза и темнового дыхания составляла соответственно 3,$1 ; 7,0 ; 5,1$ и 3,1 мкмоль $\mathrm{CO}_{2} \cdot \mathrm{M}^{-2} \cdot \mathrm{c}^{-1}$ по вариантам опыта. По данным газообмена, можно было ожидать, что продуктивность растений во 2-м и 3-м вариантах в результате будет выше, чем в остальных двух вариантах опыта.

Другие показатели световой кривой фотосинтеза дают дополнительные сведения об эффективности использования растениями световой энергии. В 1-м, 2-м и 3-м вариантах квантовый выход фотосинтеза оказался ниже 0,04 , хотя в естественных условиях произрастания растений среднее значение составляет 0,04-0,07 (31). Только в 4-м варианте квантовый выход был равен 0,046 (см. табл. 2). Наблюдаемые низкие значения квантового выхода мы связываем с формированием у растений большой листовой поверхности.

Во 2-м и 4-м вариантах интенсивность света при насыщении световых кривых фотосинтеза была выше (363 и 423 мкмоль фотонов $\cdot \mathrm{M}^{-2} \cdot \mathrm{c}^{-1}$, см. табл. 2) по сравнению с интенсивностью облучения во время выращивания (305 и 309 мкмоль фотонов $\cdot \mathrm{M}^{-2} \cdot \mathrm{c}^{-1}$, см. табл. 1). В этих вариантах Chl a работает более эффективно, поэтому скорость темновых реакций фотосинтеза в листьях верхних ярусов не стала лимитирующим фактором.

Максимальная скорость фотосинтеза на плато световой кривой у растений, выращиваемых под светодиодными облучателями, в 1-м варианте была самой низкой в сравнении с другими вариантами. Насыщение кривой скорости фотосинтеза наступало при интенсивности света $144 \pm 11$ мкмоль фотонов $\cdot \mathrm{M}^{-2} \cdot \mathrm{c}^{-1}$ (см. табл. 2), что ниже уровня интенсивности света при выращивании растений $\left(193,00\right.$ мкмоль фотонов $\cdot \mathrm{M}^{-2} \cdot \mathrm{c}^{-1}$, см. табл. 1) и связано, по-видимому, с лимитированием скорости процесса темновыми реакциями фотосинтеза.

Анализ активности световых реакций фотосинтетического аппарата по параметрам переменной флуоресценции показывает (табл. 3), что максимальный квантовый выход фотохимической реакции в ФС II $\left(\mathrm{F}_{\mathrm{v}} / \mathrm{F}_{\mathrm{m}}\right)$ был сопоставим у растений во 2-м, 3-м и 4-м вариантах и оказался несколько выше в 1-м варианте при пониженной интенсивности света. У растений, выращенных под СДО, реальный квантовый выход Y(II) первичной фото- 
химической реакции ФС II во всех вариантах был выше по сравнению с растениями под ДНаТ-600, особенно выделялись 1-й и 4-й варианты.

3. Параметры переменной флуоресценции листьев у растений огурца (Cucumis sativus L., гибрид Tристан F1) при выращивании методом аэропоники в фитотроне при разных световых и температурных режимах по вариантам опыта $(n=8$, аналитическая повторность измерений 4-кратная, $M \pm \mathrm{SEM})$

\begin{tabular}{l|c|c|c|c}
\hline \multicolumn{1}{c}{ Параметр } & $1-$ й, & 2 -й, & 3 -й, & $4-$ й, \\
& $75 \%, 23{ }^{\circ} \mathrm{C}$ & $100 \%, 25^{\circ} \mathrm{C}$ & $100 \%, 26^{\circ} \mathrm{C}$ & $100 \%, 24{ }^{\circ} \mathrm{C}$ \\
\hline Fv/Fm & $0,782 \pm 0,007^{\mathrm{a}}$ & $0,744 \pm 0,005^{\mathrm{b}}$ & $0,741 \pm 0,003^{\mathrm{b}}$ & $0,743 \pm 0,005^{\mathrm{b}}$ \\
ETR & $32,6 \pm 2,0^{\mathrm{a}}$ & $40,9 \pm 3,1^{\mathrm{b}}$ & $51,0 \pm 3,4^{\mathrm{b}}$ & $31,8 \pm 2,3^{\mathrm{a}}$ \\
Y(II) & $0,409 \pm 0,010^{\mathrm{a}}$ & $0,342 \pm 0,006^{\mathrm{b}}$ & $0,260 \pm 0,007^{\mathrm{c}}$ & $0,467 \pm 0,010^{\mathrm{d}}$ \\
NPQ & $1,020 \pm 0,100^{\mathrm{a}}$ & $0,812 \pm 0,080^{\mathrm{b}}$ & $1,019 \pm 0,110^{\mathrm{a}}$ & $0,533 \pm 0,060^{\mathrm{c}}$
\end{tabular}

П р и м е ч а н и е. Fv/Fm - потенциальный квантовый выход фотосистемы II (ФC II), ETR - относительная скорость транспорта электронов через ФС II, Y(II) - реальный квантовый выход ФС II, NPQ - коэффициент нефотохимического тушения флуоресценции хлорофилла а ФСІІ. Указаны проценты от исходной энергетической мощности светильников (1200 Вт) и фактические температуры, которые устанавливались в отсеке фитотрона в зависимости от типа и используемой мощности светильника. Характеристики фитосветильников по вариантам опыта см. рисунок, таблицу 1.

a, b, c, d Средние значения в строке, отмеченные одинаковой буквой, статистически значимо не различаются при $\mathrm{p} \leq 0,05$.

Скорость электронного транспорта (ETR) была несколько ниже в условиях светодиодного облучения, по сравнению с лампами ДНаТ-600. Более высокая скорость электронного транспорта у растений под лампами ДНаТ-600 могла приводить к увеличению синтеза высокоэнергетических эквивалентов (в частности, АТФ НАДФ-Н2), обеспечивающих высокие скорости поглощения $\mathrm{CO}_{2}$ и при интенсивности излучения в области ФАР 412,98 мкмоль фотонов $\cdot \mathrm{M}^{-2} \cdot \mathrm{c}^{-1}$ (см. табл. 1), и при высокой интенсивности облучения (1200 мкмоль фотонов $\left.\cdot \mathrm{M}^{-2} \cdot \mathrm{c}^{-1}\right)$. Одновременно в 4-м варианте (под СДО) наблюдалось снижение нефотохимического тушения (NPQ), характеризующее уменьшение тепловой диссипации, при которой световая энергия используется не на фотосинтетические процессы, а на поддержание должной скорости других биохимических реакций.

4. Показатели ростовых процессов при выращивании растений огурца (Cucumis sativus L., гибрид Тристан F1) методом аэропоники в фитотроне при разных световых и температурных режимах по вариантам опыта $(N=3, M \pm \mathrm{SEM})$

\begin{tabular}{|c|c|c|c|c|}
\hline Параметр & $\begin{array}{c}1-и ̆, \\
75 \%, 23{ }^{\circ} \mathrm{C}\end{array}$ & $\begin{array}{c}2-\mathrm{L}_{1} \\
100 \%, 25^{\circ} \mathrm{C}\end{array}$ & $\begin{array}{c}3 \text {-й (контроль), } \\
100 \%, 26^{\circ} \mathrm{C}\end{array}$ & $\begin{array}{c}4-и ̆ \\
100 \%, 24{ }^{\circ} \mathrm{C}\end{array}$ \\
\hline Высота растений, см/число ярусов листьев & $88 / 18$ & $119 / 21$ & $148 / 27$ & $101 / 19$ \\
\hline Выход урожая, кг/м²: & & & & \\
\hline на 43-и сут вегетации & $16,6 \pm 1,0^{\mathrm{a}}$ & $21,5 \pm 1,1^{\mathrm{b}}$ & $24,7 \pm 1,1^{\mathrm{c}}$ & $17,6 \pm 1,2^{\mathrm{a}}$ \\
\hline на 55-е сут вегетации & $19,4 \pm 1,1^{\mathrm{a}}$ & $27,3 \pm 1,3^{b}$ & 0 & $20,5 \pm 1,1^{\mathrm{a}}$ \\
\hline $\begin{array}{l}\text { Средняя прибавка урожая в дополнительное (по } \\
\text { сравнению с контролем) время вегетации, \% }\end{array}$ & $14,4^{\mathrm{a}}$ & $26,9^{\mathrm{b}}$ & & $16,5^{\mathrm{a}}$ \\
\hline Продолжительность периода продуктивности, сут & 55 & 55 & 43 & 55 \\
\hline $\begin{array}{l}\text { Разница температуры по сравнению с контролем } \\
\text { Отставание от контроля по срокам первого сбора }\end{array}$ & -3 & -1 & & -2 \\
\hline товарного урожая, сут & 13 & 5 & & 7 \\
\hline \multicolumn{5}{|c|}{$\begin{array}{l}\text { П р и м е ч а н и е. В каждом варианте при оценке урожайности за три цикла выращивания учитывали по- } \\
\text { казатели } 36 \text { растений. За контроль принимали 3-й вариант (лампы ДНаТ-600). Указаны проценты от ис- } \\
\text { ходной энергетической мощности светильников (1200 Вт) и фактические температуры, которые устанавли- } \\
\text { вались в отсеке фитотрона в зависимости от типа и используемой мощности светильника. Характеристики } \\
\text { фитосветильников по вариантам опыта см. рисунок, таблицу 1. } \\
\text { a, b, с Средние значения в строке, отмеченные одинаковой буквой, статистически значимо не различаются } \\
\text { при р } \leq 0,05 \text {. }\end{array}$} \\
\hline
\end{tabular}

В условиях высокой активности фотосинтетического аппарата листьев под лампами ДНаТ-600 можно было ожидать повышения скорости роста и развития растений. Действительно, при выращивании растений в аэропонных установках с ограничением по высоте (по модели «городская ферма» с высотой шпалеры 1,2 м) растения под лампами ДНаТ-600 значительно опережали растения в других вариантах как по скорости роста, так 
и по наступлению фазы плодоношения (табл. 4). Условно процесс плодоношения в эксперименте под лампами ДНаТ-600 можно разделить на три этапа. Первый этап - быстрый рост, развитие и опережение в формировании плодов по сравнению с другими вариантами, где использовали светодиоды; второй этап - активное равномерное плодоношение; третий - замедление плодоношения и остановка вегетации из-за того, что в заданных пространственных условиях растения достигли максимума высоты.

Быстрый рост и развитие растений под ДНаТ-600 привели в результате к более раннему первому сбору урожая (соответственно на 13, 5 и 7 сут) (см. табл. 4), чем при светодиодном облучении, и к опережению первого максимума сбора в 3-м варианте соответственно на 10 и 7 сут по сравнению с 1-м и 4-м вариантами.

Период вегетации и сбора урожая в варианте с ДНаТ-600 составил 43 сут (рост прекратился, так как растения достигли максимальной предусмотренной высоты шпалеры). К этому времени в варианте с ДНаТ-600 общий выход урожая (см. табл. 4) превышал таковой во всех вариантах со светодиодными облучателями: по сравнению с 1-м вариантом - на 32,8 \%, со 2-м - на 13,0 \%, с 4-м - на 28,7 \%. Для получения дополнительных данных наблюдение за растениями, которые в условиях светодиодного облучения сохраняли жизнеспособность (1-й, 2-й и 4-й варианты опыта), продлили на 12 сут (до наступления выраженного замедления продукционного процесса на 55-е сут). Прибавка составила 14,4 \% (1-й вариант), 26,9 \% (2-й вариант) и 16,5 \% (4-й вариант) относительно выхода урожая по этим же вариантам на дату завершения вегетации растений под ДНаТ-600 (3-й вариант). И только тогда (то есть по суммарному выходу продукции за 55 сут) во 2-м варианте урожай превысил таковой в 3-м варианте (ДНаТ-600) на 10,5 \%; в остальных вариантах (1-й и 4-й) суммарный выход товарной продукции за 55 сут все равно был меньше, чем у растений под ДНаТ-600 за 43 сут. При сопоставлении затрат на электроэнергию и полученной прибавки очевидно преимущество более быстрой вегетации (вариант ДНаТ-600). Полученные данные сопоставимы с общей продуктивностью этого гибрида в промышленных теплицах, где вегетация, согласно данным оригинатора, обычно длится 90-110 сут, а выход урожая состав-

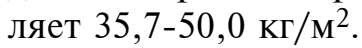

Причина укороченного вегетационного периода и соответственного понижения урожайности под лампами ДНаТ-600 связана с физиологическим старением растений (32), а также с избытком ИК-облучения. Этот фактор необходимо учитывать при выращивании растений под лампами ДНаТ-600 в условиях «городских ферм» (то есть с ограничением по высоте). Отметим, что разработанные нами аэропонная установка и технология и в этом случае имеют преимущество перед выращиванием на субстратах. Конструкция аэропонной установки позволяет приспускать стебли, располагать их внутри аэропонного желоба, что способствует увеличению объема корневой системы, омолаживанию вегетирующих растений. Однако в нашем эксперименте при использовании такого приема лампы ДНаТ-600 имели бы дополнительное преимущество, что повлияло бы на объективность сравнения ДНаТ-600 и светодиодных облучателей.

Важно отметить, что при общей автоматической регуляции температуры в фитотроне в каждом его отсеке устанавливался свой температурный градиент в зависимости от типа и мощности облучателя. Это свойство светильников влияет на весь продукционный процесс, поэтому фактическую температурную разницу решили не нивелировать. Соотношение тепловой и 
световой энергии у светодиодных и натриевых ламп различалось. По данным компании «MechaTronix Co., Ltd.» (Нидерланды), у светодиодных фитосветильников 35 \% энергии преобразуется в конвекционное тепло, $15 \%$ излучается в виде радиационного тепла и только 50 \% приходится на световую энергию в области ФАР в заданных границах спектра. У фитосветильников с лампами ДНаТ-600 коэффициент полезного действия в области ФАР составляет $34 \%$, в виде радиационного тепла излучается $55 \%$ энергии, в виде конвекционного тепла $-11 \%(33,34)$. Этот фактор также необходимо учитывать при конструировании фитотронов «городских ферм» для создания необходимых температурных условий.

Сопоставление данных по урожаю и распределению длин волн в спектрах светодиодных облучателей (см. рис.) показывает, что увеличение доли КС в диапазоне длин волн 600-700 нм приводило к повышению продуктивности растений. По интенсивности излучения в этой области светодиодные светильники во 2-м варианте превосходили светильники ДНаТ-600 на 40 мкмоль фотонов $\cdot \mathrm{M}^{-2} \cdot \mathrm{c}^{-1}$. Кроме того, максимум интенсивности светового потока внутри КС участка спектра у облучателей во 2 -м вараинте находится в области $\lambda_{\max }=660$ нм в отличие от ламп ДНаТ600, имеющих максимум при 610 нм. То есть СДО были оптимизрованы по красному спектру в длинах волн $\lambda=630-680$ нм (в области максимального поглощения хлорофилла).

Различия, которые мы наблюдали между вариантами опыта, могут быть связаны с более длительной высокой активностью фотосинтетического аппарата при медленном нарастании площади листьев и роста растений в целом. Подобная закономерность описана ранее в работе Л.Н. Чермных с соавт. (35), показавших, что у растений огурца листья с относительно низкой скоростью роста способны длительно осуществлять активный фотосинтез (в отличие от листьев, которые быстро достигают максимальных размера). Полученные нами данные свидетельствуют, что растения, выращиваемые при большей ФАР (2-й и 3-й варианты) и температуре, оптимальной для роста гибрида Тристан F1, эффективнее используют свет высокой интенсивности, чем растения в 1-м и 4-м вариантах (см. табл. 2) при температуре ниже оптимума для изучаемого гибрида. Эти результаты позволяют оценить возможность использования СДО при формировании режимов облучения растений в культивационных сооружениях различного типа. При относительно сравнимых энергетических затратах ламп ДНаТ-600 и СДО, последние выигрывают благодаря длительности использования в процессе выращивания растений (36). Однако отметим, что окупаемость СДО по сравнению с ДНаТ-600 достигается значительно позже и корректное обоснование экономической эффективности СДО в целом отсутствует. Есть сообщения (37), что применение светодиодных облучателей в долгосрочной перспективе приводило к снижению энергетических затрат (до $70 \%$ ) по сравнению с традиционными источниками света, в частности при выращивании рассады огурца (38) и саженцев и рассады декоративных культур (39). По данным других авторов, из-за высоких капитальных затрат пятилетние расходы на электроэнергию в расчете на произведенный 1 моль фотонов в 2,3 раза выше для светодиодных облучателей. Для обеих технологий расходы на долгосрочное обслуживание невелики по сравнению со стоимостью потребляемой электроэнергии (40).

Сравнение 2-го варианта опыта с 1-м и 4-м показывает, что даже небольшие изменения в спектре СДО приводят к значительным изменениям ростовых и продукционных процессов (см. табл. 4). Эти облучатели 
характеризуются меньшей (на $12 \%)$ долей синего $(\lambda=450$ нм) и большей (на $12 \%)$ долей дальнего красного $(\lambda=730$ нм) света (см. табл. 1). Также во 2-м варианте доля красного участка спектра с $\lambda=660$ нм тоже на $12 \%$ выше, чем красного с $\lambda=630$ нм (см. рис.). Примененные нами во 2-м варианте опыта СДО могут эффективно использоваться как единственный источник света при выращивании растений огурца в закрытых помещениях.

Тем не менее необходимы дальнейшие исследования, чтобы лучше понять, как растения реагируют на изменение спектрального состава света в вегетационных сооружениях (теплица, фитотрон, «городская ферма») и каким образом следует регулировать интенсивность и подбирать спектр света, чтобы, с одной стороны, ускорять продукционные процессы и получать высококачественный урожай, с другой - оптимизировать энергозатраты. В себестоимости продукта они составляют существенную долю (до $35-40 \%$, иногда и более - в зависимости от региона). Хотя на сегодняшний день светодиодные лампы для выращивания растений по эффективности не уступают традиционным лампам ДНаТ-600, до создания «идеальных» фитосветильников еще далеко. Необходимо продолжение исследований, чтобы определить регуляторную роль всех участков ФАР, влияние ближнего инфракрасного света (в дополнение к единственному источнику светодиодного света) на рост, морфологию, качество плодов и в целом на продукционный процесс у растений огурца.

Таким образом, у растений огурца при интенсивности облучения 305 и 413 мкмоль фотонов $\cdot \mathrm{M}^{-2} \cdot \mathrm{c}^{-1}$ (во 2-м и 3-м вариантах опыта, соответственно светодиодный облучатель и лампы ДНаТ-600) и температуре 25 и $26{ }^{\circ} \mathrm{C}$ формируется фотосинтетический аппарат, способный эффективно работать при повышении интенсивности света до 1200 мкмоль фотонов $\cdot \mathrm{M}^{-2} \cdot \mathrm{c}^{-1}$. Во 2-м и 3-м вариантах по сравнению с 1-м и 4-м вариантами со светодиодными облучателями (СДО) выявлены высокие значения баланса $\mathrm{CO}_{2}$ (фотосинтез-дыхание). При применении СДО реальный квантовый выход Y(II) фотосистемы II на свету выше, а скорость электронного транспорта ETR - несколько меньше, чем при использовании ламп ДНаТ-600. Во 2-м и 4-м вариантах снижался коэффициент нефотохимического тушения флуоресценции NPQ. Это позволяет понять особенности воздействия различных участков спектра на растения огурца, замедленную вегетацию растений под СДО и дать объяснение большему выходу урожая в период активного плодоношения в варианте под лампами ДНаТ-600. При облучении растений ДНаТ-600 (3-й вариант) быстрее формируется листовая поверхность, ускоряется рост растений в высоту. В этом же варианте для растений гибрида Тристан $\mathrm{F}_{1}$ характерен и более ранний выход продукции по сравнению с другими вариантами. При облучении ДНаТ-600 в условиях аэропонного фитотрона, моделирующих «городскую ферму» с ограничением по высоте размещения фитосветильника 1,5 м, вегетационный период без приспускания растений заканчивался на 12 сут раньше, чем под СДО, но выход урожая за время вегетации был выше, чем под СДО. Под СДО растения росли медленнее, что позволило продлить вегетацию еще на 12 сут (до видимого снижения продуктивности). В этот период установилось оптимальное расстояние между верхушкой растений и светильником (около 0,3 м), что способствовало высокому темпу плодоношения. В конечном итоге (с учетом дополнительного времени вегетации) СДО во 2-м варианте опыта обеспечили больший выход урожая, чем ДНаТ-600, но и энергозатраты были выше. Продолжение подобных исследований позволит определить роль разных об- 
ластей фотосинтетически активной радиации и влияние других спектральных участков (например, ближнего инфракрасного и УФ-А излучения) на продукционный процесс и качество товарной продукции у растений огурца. Это необходимо для использования СДО как единственного источника света, особенно при проектировании и создании «городских ферм».

\section{Л ИТ Е РАТ УРА}

1. Ackerman K., Conard M., Culligan P., Plunz R., Sutto M. P., Whittinghill, L Sustainable food systems for future cities: THE potential of urban agriculture. The Economic and Social Review, 2014, 45(2): 189-206.

2. Qian M., Rosenqvist E., Flygare A.M., Kalbina I., Teng Y., Jansen M.A., Strid E. UV-A light induces a robust and dwarfed phenotype in cucumber plants (Cucumis sativus L.) without affecting fruit yield. Scientia Horticulturae, 2020, 263: 109110 (doi: 10.1016/j.scienta.2019.109110).

3. Далькэ И.В., Григорай Е.Е., Головко Т.К. Эффективность использования световой энергии и продуктивность тепличной культуры огурца при досвечивании внутри ценоза. Известия ТСХА, 2014, 5: 13-23.

4. Batista D.S., Felipe S.H.S., Silva T.D., de Castro K.M., Mamedes-Rodrigues T.C., Miranda N.A., Otoni W.C. Light quality in plant tissue culture: does it matter? In Vitro Cellular \& Developmental Biology-Plant, 2018, 54(3): 195-215 (doi: 10.1007/s11627-018-9902-5).

5. Hernández R., Kubota C. Physiological responses of cucumber seedlings under different blue and red photon flux ratios using LEDs. Environmental and Experimental Botany, 2016, 121: 66-74 (doi: 10.1016/j.envexpbot.2015.04.001).

6. Garcia C., Lopez R.G. Supplemental radiation quality influences cucumber, tomato, and pepper transplant growth and development. HortScience, 2020, 55(6): 804-811 (doi: 10.21273/HORTSCI14820-20).

7. Bantis F., Smirnakoub S., Ouzounisc T., Koukounarasa A., Ntagkase N., Radogloub K. Current status and recent achievements in the field of horticulture with the use of light-emitting diodes (LEDs). Scientia Horticulturae, 2018, 235: 437-45 (doi: 10.1016/j.scienta.2018.02.058).

8. Kaiser E., Weerheim K., Schipper R., Dieleman J.A. Partial replacement of red and blue by green light increases biomass and yield in tomato. Scientia Horticulturae, 2019, 249: 271-279 (doi: 10.1016/j.scienta.2019.02.005).

9. Мартиросян Ю.Ц., Полякова М.Н., Диловарова Т.А., Кособрюхов А.А. Фотосинтез и продуктивность растений картофеля в условиях различного спектрального облучения. Сельскохозяйственная биология, 2013, 1: 107-112 (doi: 10.15389/agrobiology.2013.1.107rus).

10. Hogewoning S.W., Trouwborst G., Maljaars H., Poorter H., van Ieperen W., Harbinson J. Blue light dose-responses of leaf photosynthesis, morphology, and chemical composition of Cucumis sativus grown under different combinations of red and blue light. Journal of Experimental Botany, 2010, 61(11): 3107-3117 (doi: 10.1093/jxb/erq132).

11. Lin K-H., Huang M.-Y., Huang W.-D., Hsu M.-H., Yang Z.-W., Yang C.-M. The effects of red, blue, and white light-emitting diodes on the growth, development, and edible quality of hydroponically grown lettuce (Lactuca sativa L. var. capitata). Scientia Horticulturae, 2013, 150: 86-91 (doi: 10.1016/j.scienta.2012.10.002).

12. Piovene C., Orsini F., Bosi S., Sanoubar R., Bregola V., Dinelli G., Gianquinto G. Optimal red: blue ratio in led lighting for nutraceutical indoor horticulture. Scientia Horticulturae, 2015, 193: 202-208 (doi: 10.1016/j.scienta.2015.07.015).

13. Xie J., Liu H., Song S., Sun G., Chen R. Effects of different LEDs on photosynthesis in greenhouse cucumber. Acta Horticulturae, 2015, 1107(12): 95-100 (doi: 10.17660/ActaHortic.2015.1107.12).

14. Kang W.H., Park J.S., Park K.S., Son J.E. Leaf photosynthetic rate, growth, and morphology under different fractions of red, blue, and green light from light emitting diodes (LEDs). Horticulture, Environment and Biotechnology, 2016, 57(6): 573-579 (doi: 10.1016/j.envexpbot.2015.04.001).

15. Chen X.-L., Xue X.-Z., Guo W.-Z., Wang L.-C., Qiao X.-J. Growth and nutritional properties of lettuce affected by mixed irradiation of white and supplemental light provided by light-emitting diode. Scientia Horticulturae, 2016, 200: 111-118 (doi: 10.1016/j.scienta.2016.01.007).

16. Li Q., Kubota C. Effects of supplemental light quality on growth and phytochemicals of baby leaf lettuce. Environmental and Experimental Botany, 2009, 67(1): 59-64 (doi: 10.1016/j.envexpbot.2009.06.011).

17. Tang Y., Guo S., Ai W., Qin L. Effects of red and blue light emitting diodes (LEDs) on the growth and development of lettuce (var. Youmaicai). SAE Technical Paper 2009-01-2565, 2009: 6 (doi: 10.4271/2009-01-2565).

18. Тихомиров А.А., Шарупич В.П., Лисовский Г.М. Светокультура растений: биофизические и технологические основы. Новосибирск, 2000.

19. Kang S., Zhang Y., Zhang Y., Zou J., Yang Q., Li T. Ultraviolet-A radiation stimulates growth of indoor cultivated tomato (Solanum lycopersicum) seedlings. HortScience, 2018, 53(10): 14291433 (doi: 10.21273/HORTSCI13347-18). 
20. Smith $\mathrm{H}$. The ecological functions of the phytochrome family-clues to a transgenic program of crop improvement. Photochemistry and Photobiology, 1992, 56(5): 815-822 (doi: 10.1111/j.17511097.1992.tb02238.x).

21. Kreslavski V.D., Strokina V.V., Pashkovskiy P.P., Balakhnina T.I., Voloshin R.A., Alwaselc S., Kosobryukhov A.A., Allakhverdiev S.I. Deficiencies in phytochromes A and B and cryptochrome 1 affect the resistance of the photosynthetic apparatus to high-intensity light in Solanum lycopersicum. Journal of Photochemistry \& Photobiology, B: Biology, 2020, 210: 111976 (doi: 10.1016/j.jphotobiol.2020.111976).

22. Kreslavski V.D., Los D.A., Schmitt F.J., Zharmukhamedov S.K., Kuznetsov V.V., Allakhverdiev S.I. The impact of the phytochromes on photosynthetic processes. Biochim. Biophys. Acta Bioenerg., 2018, 1859(5): 400-408 (doi: 10.1016/j.bbabio.2018.03.003).

23. Johkan M., Shoji K., Goto F., Hahida S., Yoshihara T. Effect of green light wavelength and intensity on photomorphogenesis and photosynthesis in Lactuca sativa. Environmental and Experimental Botany, 2012, 75: 128-133 (doi: 10.1016/j.envexpbot.2011.08.010).

24. Полякова М.Н., Мартиросян Ю.Ц., Диловарова Т.А., Кособрюхов А.А. Фотосинтез и продуктивность растений базилика при облучении различными источниками света. Сельскохозяйственная биология, 2015, 50(1): 124-130 (doi: 10.15389/agrobiology.2015.1.124rus).

25. Мартиросян Ю.Ц., Мартиросян Л.Ю., Кособрюхов А.А. Динамика фотосинтетических процессов в условиях переменного спектрального облучения растений. Сельскохозяйственная биология, 2019, 54(1): 130-139 (doi: 10.15389/agrobiology.2019.1.130rus).

26. Kalantari F., Mohd Tahir O., Mahmoudi Lahijani A., Kalantari S. A review of vertical farming technology: a guide for implementation of building integrated agriculture in cities. Advanced Engineering Forum, 2017, 24: 76-91 (doi: 10.4028/www.scientific.net/aef.24.76).

27. Jishi T., Kimura K., Matsuda R., Fujiwara K. Effects of temporally shifted irradiation of blue and red LED light on lettuce growth and morphology. Scientia Horticulturae, 2016, 198: 227-232 (doi: 10.1016/j.scienta.2015.12.005).

28. Wang H., Gu M., Cui J., Shi K., Zhou Y., Yu J. Effects of light quality on $\mathrm{CO}_{2}$ assimilation, chlorophyll-fluorescence quenching, expression of Calvin cycle genes and carbohydrate accumulation in Cucumis sativus. Journal of Photochemistry and Photobiology B: Biology, 2009, 96(1): 30 37 (doi: 10.1016/j.jphotobiol.2009.03.010).

29. Prioul J.L., Chartier P. Partitioning of transfer and carboxylation components of intracellular resistance to photosynthetic $\mathrm{CO}_{2}$ fixation: a critical analysis of the methods used. Annals of Botany, 1977, 41(174): 789-800.

30. Parsons R., Ogston S.A. Photosyn Assistant. Software for analysis of photosynthesis. Dundee Scientific, Scotland, UK, 1998.

31. Гольцев В.Н., Каладжи Х.М., Кузманова М.А. Аллахвердиев С.И. Переменная и замедленная флуоресценция хлорофилла а - теоретические основы и практическое приложение в исследовании растений. Ижевск-М., 2014.

32. Kowalczyk K., Gajc-Wolska J., Mirgos M., Geszprych A., Kowalczyk W., Sieczko L., Gajewski M. Mineral nutrients needs of cucumber and its yield in protected winter cultivation, with HPS and LED supplementary lighting. Scientia Horticulturae, 2020, 265: 109217 (doi: 10.1016/j.scienta.2020.109217).

33. Lighting comparison: LED vs high pressure sodium/low pressure sodium. Режим доступа: https://www.stouchlighting.com/blog/led-vs-hps-lps-high-and-low-pressure-sodium. Дата обращения: 10.06.2021.

34. Advanced thermal management for LED grow lights. Режим доступа: https://www.hortigrowlight.com/en-gb/advanced-thermal-management-led-grow-lights. Дата обращения: 10.06.2021.

35. Чермных Л.Н., Чугунова Н.Г., Кособрюхов А.А., Карпилова И.Ф., Чермных Р.М. Взаимосвязь ростовых процессов и фотосинтеза в онтогенезе листа огурцов при действии пониженной ночной температуры. Физиология растений, 1980, 27(5): 1101-1109.

36. The DesignLights Consortium. Horticultural lighting qualified products list. Режим доступа: https://www.designlights.org/horticultural-lighting/. Дата обращения: 30.03.2020.

37. Pattison P.M., Hansen M., Tsao J.Y. LED lighting efficacy: status and directions. Comptes Rendus Physique, 2018, 19(3): 134-145 (doi: 10.1016/j.crhy.2017.10.013).

38. Jinxiu S., Qingwu M., Weifen D., Dongxian H. Effects of light quality on growth and development of cucumber seedlings in controlled environment. International Journal of Agricultural and Biological Engineering, 2017, 10(3): 312-318 (doi: 10.3965/j.ijabe.20171003.2299).

39. Randall W.C., Lopez R G. Comparison of supplemental lighting from high-pressure sodium lamps and light-emitting diodes during bedding plant seedling production. HortScience, 2014, 49(5): 589-595 (doi: 10.21273/HORTSCI.49.5.589).

40. Nelson J.A., Bugbee B. Economic analysis of greenhouse lighting: light emitting diodes vs. high intensity discharge fixtures. PLoS ONE, 2014, 9(6): e99010 (doi: 10.1371/journal.pone.0099010).

1ФГБНУ Всероссийский НИИ сельскохозяйственной

Поступила в редакцию

биотехнологии, 25 августа 2021 года 
127550 Россия, г. Москва, ул. Тимирязевская, 42,

e-mail: levon-agro@mail.ru, valentbond@mail.ru, yumart@yandex.ru $\bowtie$;

2ФИЦ ПНЦБИ, Институт фундаментальных проблем

биологии РАН,

142290 Россия, Московская обл., г. Пущино, ул. Институтская, 2,

e-mail: kosobr@rambler.ru;

${ }^{3}$ ФГБУН Институт биохимической физики

им. Н.М. Эмануэля РАН,

119334 Россия, г. Москва, ул. Косыгина, 4

Sel'skokhozyaistvennaya biologiya [Agricultural Biology], 2021, V. 56, № 5, pp. 934-947

\title{
THE INFLUENCE OF DIFFERENT LIGHT SOURCES ON PHOTOSYNTHETIC PERFORMANCE AND PRODUCTIVITY OF Cucumis sativus L. HYBRID TRISTAN F1 IN AEROPONIC PHYTOTRON FACILITIES
}

\author{
L.Yu. Martirosyan 1, 3, A.A. Kosobryukhov', 2, V.V. Martirosyan' ${ }^{1}$, Yu.Ts. Martirosyan $1,3 \bowtie$
}

${ }^{1}$ All-Russian Research Institute of Agricultural Biotechnology, 42, ul. Timiryazevskaya, Moscow, 127550 Russia, e-mail levon-agro@mail.ru,valentbond@mail.ru,yumart@yandex.ru ( $\square$ corresponding author);

${ }^{2}$ Federal Research Center Pushchino Scientific Center for Biological Research RAN, Institute of Basic Biological Problems, 2, ul. Institutskaya, Pushchino, Moscow Province, 142290 Russia, e-mail kosobr@rambler.ru;

${ }^{3}$ Emanuel Institute of Biochemical Physics RAS, 4, ul. Kosygina, Moscow, 119334 Russia

ORCID:

Martirosyan L.Yu. orcid.org/0000-0003-1769-6377

Kosobryukhov A.A. orcid.org/0000-0001-7453-3123

Martirosyan V.V. orcid.org/0000-0003-1178-8887

The authors declare no conflict of interests

Acknowledgments:

The work was carried out according to state order No. 0574-2019-0002.

Received August 25, 2021

doi: 10.15389/agrobiology.2021.5.934eng

\section{Abstract}

Global climate change and anthropogenic pollution of the environment pose serious problems for agricultural producers. Drought or flooding of fields, the emergence of new diseases and pests, and reduction of agricultural land pose serious problems in providing food for the growing population. Moreover, more than half of the world's population lives in cities, and this proportion is expected to increase to $67 \%$ at 2050. To meet the growing needs of the population of megacities, new non-standard approaches and technologies are needed to increase the production of fresh vegetables, fruits, and berries. Vertical plant growing in the so-called "city farms" is a promising resource-saving method of compact multi-tier cultivation of various plants, especially greens, vegetables, medicinal and ornamental plants. The use of hydroponics and aeroponics allows a new type of agriculture that combines biotechnology, industrial architecture, design and successfully integrates into urban infrastructure. A significant increase in the production and yield of basic food vegetable crops, especially in "city farms" necessitates understanding needs of plants for light, mineral nutrition and other equally important factors, e.g., temperature, humidity, $\mathrm{CO}_{2}$ content. Under the conditions of a phytotron that imitates a "city farm" model, we compared the effects of high-pressure sodium lamps (HPSLs) DNaT-600 traditional for greenhouse plant lighting and alternative light-emitting diode phytolamps (LEDs) on photosynthesis and, ultimately, the production process in Cucumis sativus L. Tristan F1 hybrid as a cucumber crop usually cultivated in greenhouses. In treatments 2 and 3, LED irradiators and DNaT-600 lamps at a radiation intensity of 305 and $413 \mu \mathrm{mol}$ photons $\cdot \mathrm{m}^{-2} \cdot \mathrm{s}^{-1}$ and a temperature of 25 and $26{ }^{\circ} \mathrm{C}$, respectively, provided formation of an effective photosynthetic apparatus capable of performing at an increase in light intensity up to $1200 \mu \mathrm{mol}$ photons $\cdot \mathrm{m}^{-2} \cdot \mathrm{s}^{-1}$. The LEDs of treatment 2 can serve as a single light source when growing cucumbers in a "city farm". These irradiators are characterized by a smaller proportion of blue $\left(\lambda_{\max }=450 \mathrm{~nm}\right)$ and far red $\left(\lambda_{\max }=730 \mathrm{~nm}\right)$ light and a larger proportion of red $(\lambda \max =660 \mathrm{~nm})$ light in the spectrum. However, for early harvesting, the DNaT-600 lamps with the standard plant lowering method are preferable. The period of growing plants under DnaT-600 irradiation in the "city farm" simulating aeroponic phytotron with a limitation of the phytolamp height of $1.5 \mathrm{~m}$ without plant lowering, ended 12 days earlier than under LED irradiators. Nevertheless, the yield during the growing season was higher for DNaT-600 than for LED irradiators with the same energy consumption. The data obtained are helpful in the design and creation of modern biotechnological enterprises, such as vertical "city farms" for the food production and biotechnological enterprises for production of biopharmaceuticals.

Keywords: Cucumis sativus L., photosynthetic apparatus, LED phyto lamps, growth processes, aeroponic phytotron, city farms. 